\title{
Efecto del consumo del extracto de haba (Vicia faba L.) en el aumento de leucocitos, en ratones
}

\author{
Effects of broad bean (Vicia faba L.) extract consumption on leukocytes increase in mice
}

\author{
Jony Amaro Terrazos ${ }^{1, a}$, Ítalo Moisés Saldaña $a^{2, b}$ \\ 1 Institución Educativa 1182 "El Bosque", Lima, Perú. \\ 2Departamento de Patología Clínica, Servicio de Bioquímica, Hospital Nacional Edgardo Rebagliati Martins, Lima, Perú. \\ ${ }^{a}$ Doctor Ciencias de la Educación; Especialidad Biologia y Química; ${ }^{b}$ Tecnólogo Médico, Químico farmacéutico.
}

An Fac med. 2015;76(4):465-6 / http://dx.doi.org/10.15381/anales.v76i4.11421

\section{SR. EDITOR:}

Hemos leído con interés el artículo publicado por Amaro, donde se demuestra que existe un incremento de los leucocitos al administrar la betarraga en ratones albino de la especie Mus musculus de la cepa Balb/c ${ }^{(1)}$.

Queremos compartir los resultados de un estudio en el que se utilizó la haba (Vicia faba L.), un vegetal que cumple el rol en la alimentación del poblador rural y urbano por su aporte en proteínas, característico de toda leguminosa, y por su contribución en carbohidratos, minerales y vitaminas. La importancia de esta especie alimenticia se acrecienta porque también participa con los subproductos de la cosecha en la alimentación del ganado vacuno, ovino, porcino y de cuyes, así como mejorador de la fertilidad del suelo, aumentando los rendimientos de otros cultivos que le suceden en la rotación ${ }^{(2)}$.

Se elaboró el extracto acuoso del haba seca de acuerdo al protocolo descrito por Alzamora ${ }^{(3)}$, con algunas variantes. Las habas seleccionadas fueron secadas en estufa de aire circulante a una temperatura de $45^{\circ} \mathrm{C}$, durante 25 días. Una vez desecado se procedió a la operación de atomización, en molino manual. Finalmente, se tamizó para conseguir un polvo fino que fue conservado en recipientes para la preparación del extracto. Para el tratamiento de los animales con el extracto se elaboró la solución a una concentración de 250 $\mathrm{mg} / \mathrm{kg}$, diluyéndolo en agua destilada, y se conservó a $-4^{\circ} \mathrm{C}$; se preparó las dosis en volúmenes de $2 \mathrm{~mL}$.

Se utilizó 20 ratones albinos de la especie Mus musculus de la cepa Balb/c, machos, de 24 g peso promedio, procedente del bioterio del Instituto Nacional de Salud (Lima-Perú), que fueron manejados de acuerdo con el protocolo de la Comisión Ética para la Experimentación Animal de la Universidad del País Vasco ${ }^{(4)}$. Se trabajó con dos grupos -experimental y control- de 10 ratones cada uno. Al grupo experimental se le administró por vía oral el extracto de Vicia faba L., volumen de 2 $\mathrm{mL}$, en dosis de $250 \mathrm{mg} / \mathrm{kg}$ cada cinco horas, durante una semana, alternando con alimento estándar procedente del Instituto Nacional de Salud (Lima-
Perú), en dosis y tiempos de acuerdo a normas estándar. Al grupo control solo se le administró el alimento estándar, en dosis y tiempos iguales al grupo experimental. Después del periodo de acondicionamiento de 48 horas, administrando solo alimento estándar y agua a ambos grupos, se hizo la pre-medición. Se extrajo las muestras de sangre para evaluar el número de leucocitos. Se utilizó el método de fórmula leucocitaria Schilling y la técnica frotis, de acuerdo al Laboratorio de Análisis Clínico de la Facultad de Farmacia y Bioquímica de la Universidad Nacional Mayor de San Marcos. Luego de aplicar el experimento, se realizó la posmedición. El recuento de leucocitos fue sometido a un análisis de media, seguido

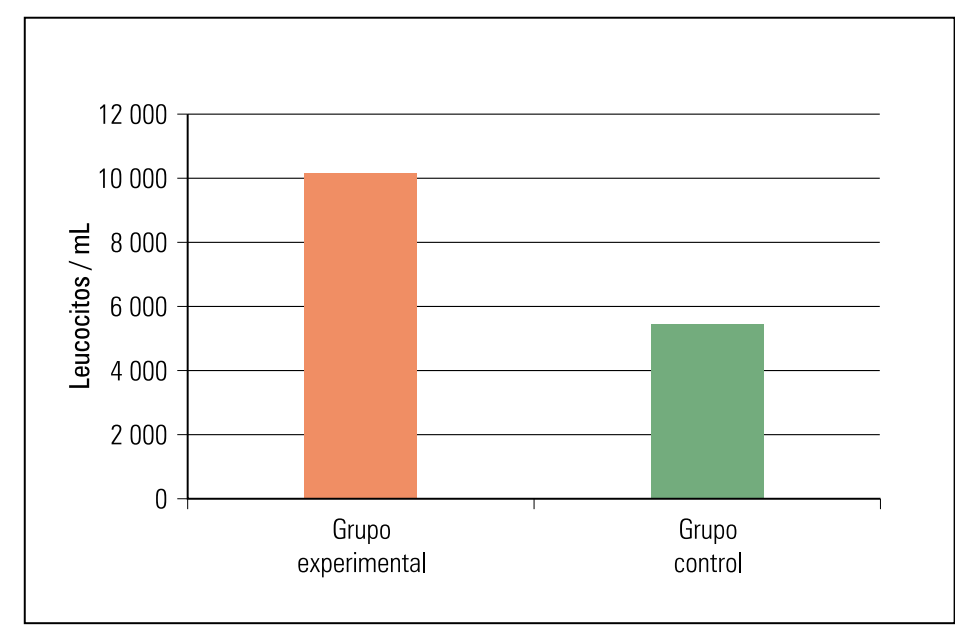

Gráfica 1. Efecto del consumo de extracto de haba (Vicia faba L.) en el grupo experimental frente al grupo control. 
de una prueba t student, para buscar diferencias significativas. Se consideró que existió diferencias significativas cuando $\mathrm{p}<0,05$. Los resultados de los experimentos son presentados como la media \pm el error estándar.

$\mathrm{Al}$ administrar al grupo experimental el extracto de haba por vía oral, volumen de $2 \mathrm{~mL}$ cada cinco horas durante una semana, alternando con su alimento estándar, se observó incremento de la media $(10121+209,2)$ frente al grupo control $(5430,1+422,8)$, con diferencia significativa ( $t$ student $\mathrm{p}<0,05$ ) (gráfica 1), de forma similar el efecto que produce la betarraga.

La presencia de flavonoides en la composición en la betarraga como en las habas ${ }^{(1,5,6)}$ explicaría el incremento de leucocitos. Basados en estos resultados encontramos conveniente que se realice mayor investigación relacionando las habas.

\section{REFERENCIAS BIBLIOGRÁFICAS}

1. Amaro J. Influencia de la betarraga (Beta vulgaris var. cruenta) en el aumento de leucocitos, en ratones. An Fac med. 2014;75(1):9-12.

2. Ramírez VM. Curso cultivo de cebada y habas. Programa sectorial Agropecuario Capacitación. Inipa-Cipa. 1983. Código F01.C87C. Universidad Nacional Agraria La Molina.

3. Alzamora L, Ávila G, Colona E, Garcia J, Alzamora D. Inmunoestimulación con extracto acuoso de Lepidium peruvianum (maca) en ratones inmunosuprimidos con ciclofosfamida. XIII Reunión Científica ICBAR, Libro de Resúmenes, 127.

4. Comité de Ética de Experimentación Animal (CEEA/AAEB). Ética en la Investigación con animales. Disponible en: http://www.ikerkuntza. ehu.es/p273-sheticct/es/contenidos/información vri_ceba/es_vri_etic/normativa.html.

5. Bekkara F, Jay M, Viricel MR, Rome S. Distribution of phenolic compounds within seed and seedlings of two Vicia faba cvs differing in their seed tannin content, and study of their seed and root phenolic exudations. Plant and Soil. 1998;203(1):27-36.
6. Agurto Arias ES. Análisis de compuestos antioxidantes presentes en haba (vicia faba L.) para su consumo hortícola.[Tesis Profesional].Santiago: Facultad de Ciencias Agronómicas, Universidad de Chile; 2012.Disponible en:http://www tesis.uchile.cl/bitstream/handle/2250/112221/ An $\%$ C $3 \%$ A 1 lisis $\% 20$ de $\% 20$ compuestos $\% 20$ antioxidantes $\% 20$ presentes $\% 20$ en $\% 20$ haba $\% 20$ $\% 28$ Vici.pdf?sequence=1 .

Carta al Editor recibida el 8 de agosto de 2015.

Financiamiento: Autofinanciado.

Conflictos de intereses: Los autores declaran no tener conflictos de intereses.

Correspondencia:

Jony Amaro Terrazos

Dirección: Mz B1 Lote 14 Sargento Lorenz San Juan Lurigancho

Teléfono: 2867856-955119117

Correo electrónico: jony200927@live.com 